\title{
Urban environment factors in advertising poster in Ho Chi Minh City
}

\author{
Thi Viet Ha Nguyen ${ }^{1, *}$ \\ ${ }^{1}$ University of Architecture Ho Chi Minh City (UAH), 196 Pasteur, Ward 6, District 3, Ho Chi Minh \\ City, Vietnam
}

\begin{abstract}
Poster design is an important part in graphic design and contributes considerably to the "green industry" - the modern advertising industry. In the era of International Integration of Vietnam, there is a large number of changes in advertising posters, and Urban Environment factors plays a very important role in this process. Advertising poster is integrated with visual languages, creating a totally new outlook on aestheticism. Special attention has given to the Urban Environment factors, and they have even become a trend, spreading to the art of design, particularly in advertising posters. The article analyses how Urban Environment factors have been expressed in advertising posters, especially in graphic elements, from concept to execution. The article focuses on Commercial Advertising Posters which is used for brands available in Vietnamese market from 2010 till now (2017). The area of research is Ho Chi Minh City, where there is a diversity of market trends and also a place which is greatly and quickly influenced by new trends in Art and Design. This is also considered as the place that can quickly absorb new trends of Arts and Culture in creating Advertising campaigns for Vietnamese market. Besides, Ho Chi Minh City is the leader in development of modern society for Vietnamese; there are many construction projects for skyscraper, plazas, living space, security for storage of belongings and for comfortable life and work of urban population.
\end{abstract}

\section{Introduction}

Advertising poster is a category of graphic design created by combining graphic elements to form a key image in order to have messages, which help to increase the sales of a product or services. It is not only new ideas but also the diversity of creativity that made advertising poster unique in; and it is not only special on aesthetics but also on the harmony of beauty and Urban Environment factors that are created for the specific business goal.

In terms of art, advertising poster uses visual elements in order to create the general concept and use visual languages to construct the key image. On the top of that, the success of advertising poster depends on design methodology that shows brand's characteristic, and suitable with the awareness of contemporary aesthetics in Ho Chi Minh City Urban Environment.

\footnotetext{
*Corresponding author: vietham97@gmail.com
} 
In art history, advertising poster varied according to different milestone of eras. Nowadays, with a large diversity of graphical styles, the new and outstanding methods of Urban Environment factors such as rules breaking, interaction and variation have changed creative thinking and made a large diversity for advertising poster in terms of applied art. Generally, it is easy to see a remarkable outbreak of commercial posters that have Urban Environment factors.

For advertising poster, aesthetic and non-aesthetic factors are connected to each other that form the subject of research. As a result, they formed a subject matter that researcher studied for the article. Firstly, as advertising poster is an artwork of applied art, in order to study about aesthetic factors, the non-aesthetic features also should be analyzed. Secondly, the research studied the relationship of aesthetic and non-aesthetic factors in order to define artistry are the mostly focused and highest expression of aesthetics. Thirdly, in terms of advertising posters' characteristic, the aesthetics cannot be distinguished from the nonaesthetics in research's because the shortage of domestic research on graphic design. In order to make it clear, the research should focus not only the meaning itself but also on contents and form in Urban Environment, which make an artwork more valuable.

It is considered that advertising poster in Vietnam is keen, innovatory and developing alongside with the market economy when looking at the integration of Vietnamese posters to the international design trend. Inspire of the late beginning, more than ten years later than the world, graphic design of Vietnam can keep up with that of the world. As the speedy changing trends of Vietnames advertising posters, the study and learning of the movement of poster's aesthetics including facts, causes, nature and results etc., are meaningful and practical. Especially, this study uses the current point of view to compare the changes of advertising posters in Ho Chi Minh city. This is the gap that help authors to form and to develop suppositions of the article, which contribute to create basic theories of poster to be applied in education and reality.

\section{Materials and methods}

The article uses interdisciplinary research methodology. With the following operations: Information collection, Material analysis, Analysis of works, Experimental research, Interviewing, Qualitative methods, Quantitative methods, Comparative methods, design methods, etc.

\section{Results}

Currently, the research process has shown that "Urban Environment factors in Advertising Poster in Ho Chi Minh City" is a new study approach and there is no other similar overall study on Urban Environment in Advertising Posters in Ho Chi Minh City. The article uses practical research, from empirical study to have assumption and then reached core value of matter. Specifically, the research goes throughout all the concepts, general ideas of advertising posters, Urban Environment factors both in Ho Chi Minh and on a global scale. From that view, the research shows the existence and the quantities of Urban Environment factors in creating and appreciating advertising posters.

By analyzing the current artworks, the article illustrates the effects of Ho Chi Minh city Urban Environment factors in Advertising posters. To be more specific, these factors is Urban Environment makes changes in how viewers appreciate Artwork in the Age of IT. These factors lead to new approach in creating advertising poster: Breaking the rules, Interacting, three-dimensional look, three-dimensional Mock-up, Mixed medium, Variation, etc. Because of those characteristic of urban lanscape factors, designers have had more 
approach of creation and new can create new kind of artworks to communicate with viewers. The contents and images of advertising posters are lively, realistic, polysemous and closed to current pace of life.

From artistic points of view, the article firstly focuses the relationship between function (urban environment) and Fine Art. They are the main reasons to create the change of applied art in the era of technology. From the view of applied art, thanks to Urban Environment factors, viewers now can interact with poster or even cooperate with designer in order to appreciate applied art. These are objective points of view to acknowledge that urban environment have had big effects not only on the way to create Artwork but also on financial factors. Besides, urban environment factors have highly enhanced social awareness in the era of globalization.

\section{Discussion}

\subsection{The foundational arguments and reality of urban environtment factors in advertising poster}

Poster: Bases on is a different type of dictionaries such as English-Vietnames dictionary, French - Vietnamese dictionary, Dictionary of Fine Art, poster can be considered as a type of Graphic design which is a category of Applied Art. In Vietnames, it is called as: affiché, poster, bích chương, tranh cổ động, ect. In term of function, poster is form of informationspread which has a specific purpose and is placed publicly to common viewers.

Advertising posters: In terms of marketing, advertising posters are used as methods of branding, introducing products and sending messages to customers. They are paid to create messages for commercial purposes with some requirements such as: places, positions and the contents of advertising for a period of time. The contents of these posters are brands, products or services.

Nowadays, advertising posters diverse widely on both content and form. They are not only made to hang on walls, on roads but also to display in other ways such as: 2 sidesprinted, widen the creativity, blurry the boundary of different types of art, apply changing effects, interaction, space-arrangment, co-techniques, high-tech materials, ect ... in urban landscape.

Currently, the word "poster" is used widely in education as well as advertising industry. In order to make the articles close to reality, the word "Advertising posters" will be used as a common term that is used for commercial communication (including content and form, size and material).

Types of posters: Poster is a mean of communication which is widely used in different fields such as advertising, propaganda, information, movie any theater, etc.. Each kind of poster is applied for different cases such as propaganda poster for political - social environmental purposes, or advertising poster for commercial messages. Based on different usages, each type has its specific characteristic such as: information in propaganda, selling products in advertisement.

Some features of advertising poster: Advertising poster is a work of co-oporation between artistry and the economy, a combination of different features that affect the aesthetics of the artwork. Throughout the reality of development, the specific characteristics of advertising poster can be remarked with some characteristics such as communications, commerce, aesthetics and feasibility.

In general, art can be divided into two trends: art for art's sake and art for life's sake. In art for life's sake, the distinguished features that create the differences between these purposes are not only the aesthetics, but also the applicability that can satisfy the 
requirements of human in modern society. They emphasize the specific characteristics of industrial design, a kind of visual art including advertising poster.

Obviously, recognizing the artistic value of advertising poster should base on the key image that applied different methods of visual combinations with the materials such as lines, colors and shapes and forms. Specially, urban environment element is an important.

Conception of urban environment, urban environment elements in art creativity

An urban environment is the environment of a city; usually characterized by many buildings in a limited amount of space, with a high per capita per square mile. Most of the living spaces, working spaces, shopping areas, educational facilities, services, etc. are grouped in close proximity to each other.

The concept refers to a period of development in public, environment, science, technology and art of human being. It was introduced when the modern doctrines had become need for life, and they were in comfortable circumstances. According to article, Ho Chi Minh City called as a big Urban environment in Vietnam and one of the most trendy terms on mass media. This place have many modern buildings in a limited amount of space, with a cresmall, plaza and showroom, ect. Among the theory of design of advertising, especially epistemological deconstruction, upholding "communicative competence and the ability to create situations in communication" is to make changes in form and concept art, particularly in advertising poster today.

In terms of art, according to some researchers, the urban environment graphic design's expressions were assumed to appear from 1910 to 1920 . The time of 1960 to 1970 seem to be the peak of the break rule of art, created a movement which affects widely in art creativity around the world.

These radical concepts had strongly influenced art creativity, created lots of trends. In its early phases it was most associated with sculpture - especially Site - specific art, Land art and Arte - having arisen out of mounting criticism of traditional sculptural forms and practices that were increasingly seen as outmoded and potentially out of harmony with the natural environment. Contemporary art might often pop up unexpectedly, but now cities all over the world are finding there is much to be gained from so-called 'street' art. In Vietnam, according to researchers, at that time, urban environment element was not appreciated with its true essence and they had begun to affect the works of art in from the beginning of 1990s and developed after 2000s.

Urban environment factors in advertising poster

The advertising posters expressions are always open with art trends in general and in particularly with designs that have urban environment elements, including these following significant factors of ambient advertising, interactive street advertising:

Focusing on the illogicality, human's satisfactions, surprising amazement, weirdness, humorousness, etc, in living environment, making instantly emotions.

Focuses on the role of knowledge and deconstruction method in order to represent social reality. Therefore, scientific approach is the best way to analyze the structure of all the events that happen in nature, social, human and even in creating art.

Focuses on the conceptions, philosophy used in design, which made poster be "directed" from the expression to the presumption's results in public, that is the media trend.

With the conception of freedom, breaking the rules, irregularity, blurring all the subject's barriers by showing the desire, creating strong impact, expressing public awareness. The approach of this factor focuses on the randomness, moment of movement, interaction, those types were designed based on the environment and situation of advertising subject. These advertisements expressed naturally in urban environment, appreciate the differences in thinking in the approaching social reality. Art in public spaces, if it's good, can add a new layer of emotion to a city, something outside the practical business of day-to-day living. 


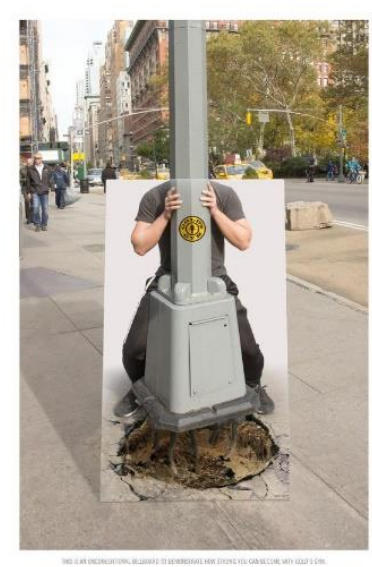

Fig. 1. Gold's Gym: A stronger you, $1 \mid$ Ads of the World ${ }^{\mathrm{TM}}$ Credits: Advertising School: School of Visual Arts, New York, USA Creative Directors: Jack Mariucci, Bob Mackall Art Director / Photographer: Taejun Park Copywriter: Nobuaki Nogamoto (https://www.pinterest.com/pin/ 529665606159345187/ (3:00PM, 7.8.2017)).

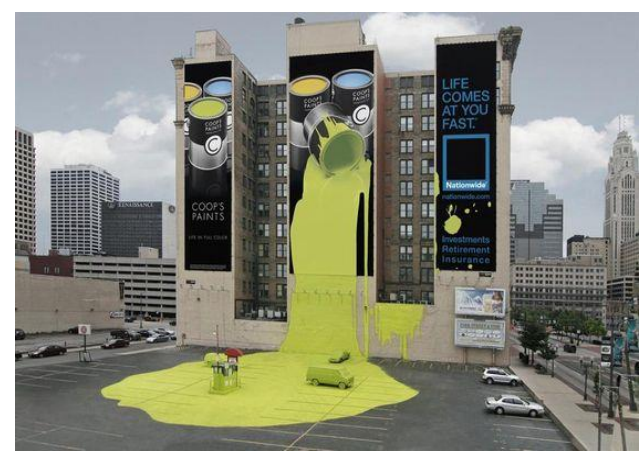

Fig. 3. High building is become billboard art (https://www.pinterest.com/pin/1237083209845400 98/ (3:20PM, 7.8.2017)).

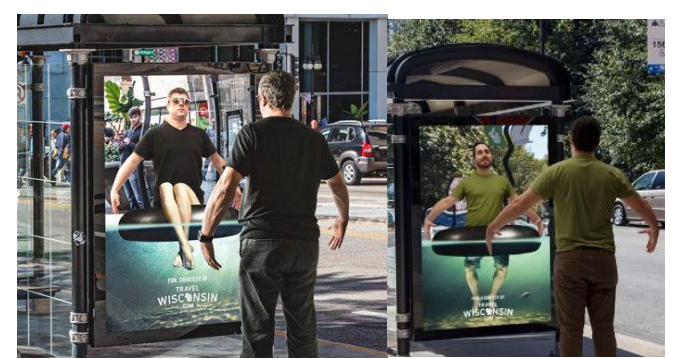

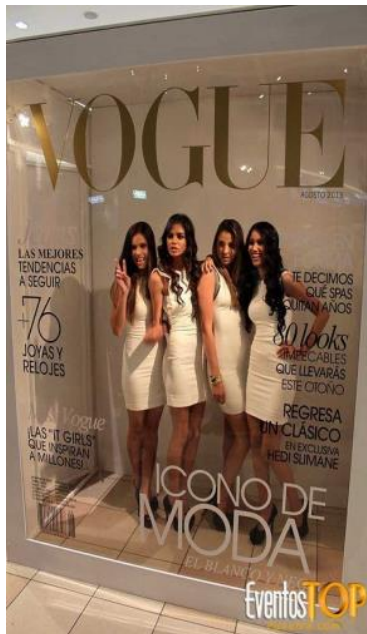

Fig. 2. Vogue magazine: The action of calling something to the attention of the public especially by paid announcements (https://www.pinterest.com/pin/ 272608583671572520/ (3:15PM, 7.8.2017)).

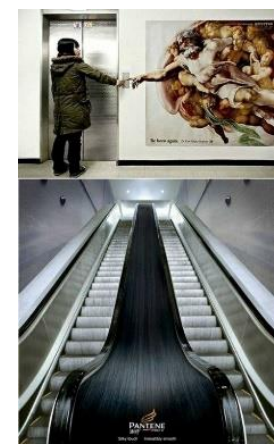

Fig. 4. See more about the amazing world around you with these one hundred interesting facts that are guaranteed to tantalize your mind (https://www.pinterest.com/pin/ 163325923966829451/ (8:10AM, 6.8.2017)).

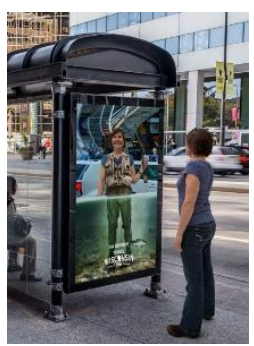

Fig. 5. Clever use of guerrilla advertising to convey a message. It makes the person interact, and gets them thinking more about vacationing in Wisconsin (http://www.arcreactions.com/, https://www.pinterest.com/pin/107875353554571581/ (8:15, 8.2017)). 


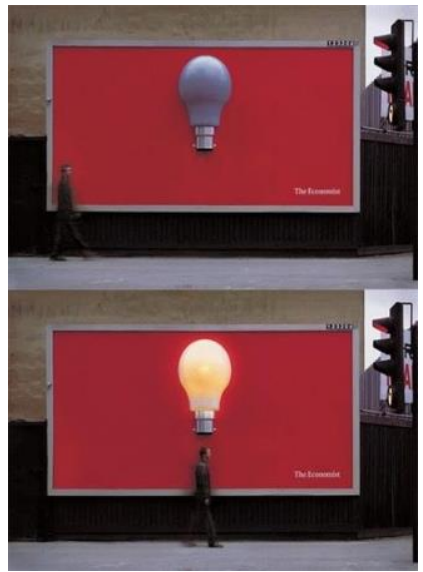

Fig. 6. Really good interactive street advertising. This bright idea is from The Economist has the bulb lighting as someone passes under it. Pinned by Ignite Design \& Advertising, Inc. (www.clickandcombust.com, https://www.pinterest.com/pin/ 220254237999638642/(8:34A M, 7.8.2017)).
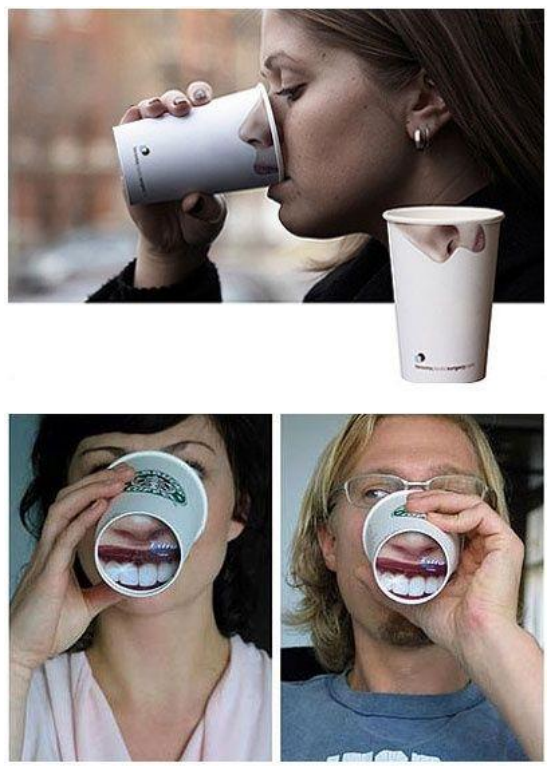

Fig. 7. Tickle your audience's funny bone with humorous and memorable advertising

(https://designschool.canva.com/blog/funnyads/?utm_content=buffer $478 b 7 \& u t m \_$medium $=$soc ial\&utm_source=linkedin.com\&utm_campaign $=b u$ ffer (5:00PM, 8.8.2017)).

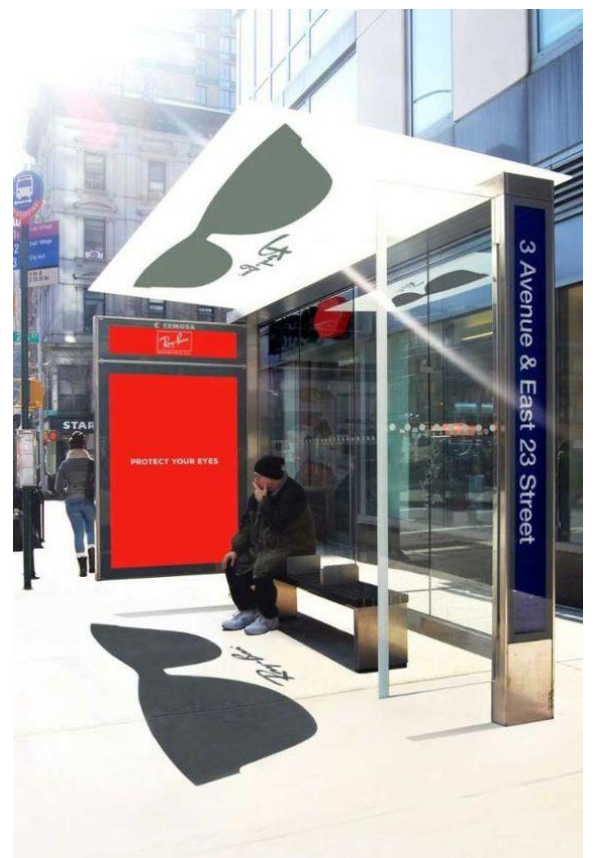

Fig. 8. We're always looking for new inspiration, and looking at creative advertising is certainly a great way to get inspired. Check out this little collection that. Published January 19, 2016. Written by Charlie (https://theultralinx.com/2016/01/23-excellent-examples-of-creative-advertising/, https://www.pinterest.com/pin/508062401692642903/ (7.8.2017)). 
Commodities exchanges always attach to advertisement and poster was the earliest methods. It represents the quick development in technology and life style, as well as consumer's taste and design methodology. Advertising poster was formed along with the development of writing, printing techniques, which developed with human's civilization and commercialization. In the $60 \mathrm{~s}$ and $70 \mathrm{~s}$ of the 20 th century, art history saw new perspectives in art creativity and they were considered as being outrageous with the desire to change, to finish the domination of Functionalism", they were urban environment elements. Until the $80 \mathrm{~s}-90 \mathrm{~s}$, the decades applied the extraordinary changing of technology, making important changes in international art and applied art, marking the birth of a lot of art styles, which are considered as sudden changes. In the 21 th century, the striking development of the industry had impulse the development of advertising poster. Remarkably the advertising posters which contain urban environment factor is more and more expanded.

The development of advertising poster in Vietnam

The development of advertising posters in Vietnam can be recognized through the historical reflection of the era. Before the year 1986, advertising posters were not formed clearly because the Vietnam War and the economy was mostly isolated from the world. After 1986, our country turned to the renewed periods, the government established new policies, which were more open and internationally integrated. As a result, the artworks of Vietnameses artists had made big changes, more open-minded. Besides propaganda posters, commercial posters started to appear with more quantities than before, but the artistic characteristics were unremarkable. In the period of 1995 to 2000, the time of free market orientation, advertising posters became more popular. However, the expression of these posters still focused on information with full-text billboards, similar format that were uncreative and poor performance. From 2000 to 2010, advertising posters became popular in the whole country, especially in Ho Chi Minh City, the form of these posters already had some changes but urban environment factor was unremarkable.

After some periods of exploration and experiment, in 2010, it was clearly seen the changes in creativity trend, in which used varieties of art's languages especially with some experiment on urban environment factors. After joining WTO (World Trade Organization), Vietnam market integrated with the global economy, it was bombarded with many great scientific breakthroughs that led to the changes of consumers' predilection. There was a broke out of environmental art elements through different approaches, especially in form in urban environment, that drew more public's attention. Moreover, the arrival of international brands and companies, especially international advertising agencies have created new appearance for advertising poster in Vietnam from that year on.

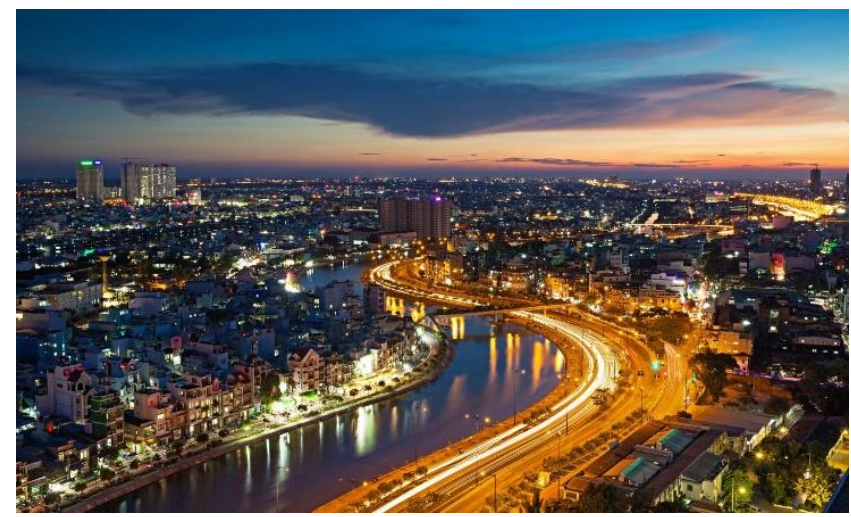

Fig. 9. https://www.bing.com/images/search?view=detailV2\&ccid=ghzy9HP\%2f\&id=1E65FFA 864DC9D70F965929352269E314C77AAD2\&thid=OIP.ghzy9HP_rtH9URsSAH4rbQFBDC\&q=hoc himinh + city\&simid $=607994588558263941 \&$ selectedIndex $=12 \&$ ajaxhist $=0(3: 07 \mathrm{PM}, 7.8 .2017)$. 
Throughout the history, advertising posters resigned for propaganda posters used for war resistance and united nation purposes. When the economy was open and globalized (from 2010 until now), Vietnam society developed to a higher level with new features for an advanced economy and a globalized society.

In that diversified changing, advertising posters can be separated into two trends, tradition and modern. The traditional style with its long terms history in Vietnames fine art used to have directed voice that show honesty, ordinary, vulgarization that closed to the common people. This directed communication style with less creative thinking, somehow satisfied the simple awareness of the society.

On the other side, the different changes such as the international integration economy, the advanced society, the improvement of public's awareness and the generational transference, etc., led to new requirements in artistic taste of common people. Traditional advertising posters became impoverished with boring form, melodramatic contents and old communication method, which strictly promoted stiff and boring shapes. These styles could not survive in the environment of images differences 'competition currently. The strong changes in forms of advertising posters with urban environment factors became more suitable with the requirement of business purpose and reality life because they are not only honest, vulgarized and popular but also revolutionized. They are signals of changes in the art of advertising posters that stimulates the creativity and always looking for new ways of expression.

In general, the researches and related definitions drew an overall picture about advertising posters in environment. As we can see, in the period of integration, advertising posters have lots of changes including urban environment element.

Nowadays, it is bombarded with new trends in form and creative thinking in advertising poster in Vietnam. Those changes are creating more values in art, economy and society. And in any reference system, advertising poster with urban environment element is a noncontroversial term in the reality of current creation.

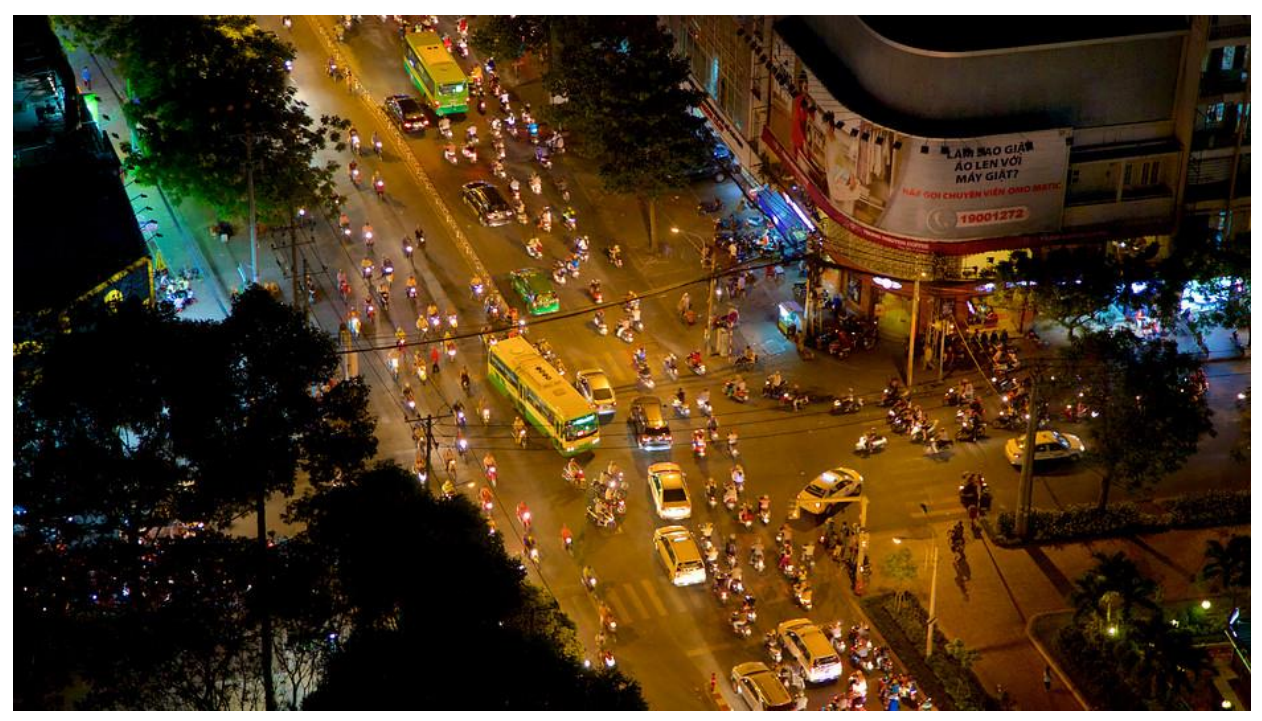

Fig. 10. https://www.bing.com/images/search?view=detailV2\&ccid=6bbwFIB\%2f\&id=9DF31027 E8DC45718E471DB2A1CF9C0375EEB2C6\&thid=OIP.6bbwFIB_JgZp8B0aOX5iUwEsCo\&q=ho+ chi + minh + city\&simid $=608023162958777622 \&$ selectedIndex $=85$ (3:07 PM, 7.8.2017). 

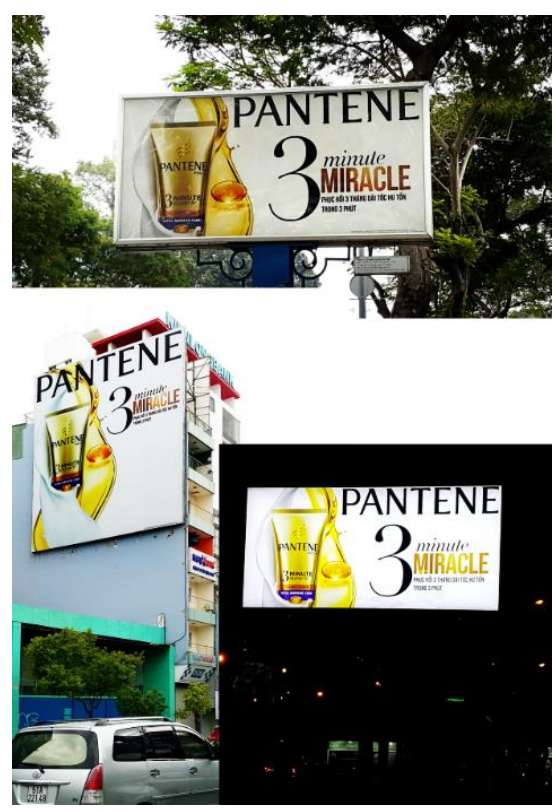

Fig. 11. Author took a photographs on Le Loi Street, District 1, Ho Chi Minh City, Vietrnam. (3:20PM, 6.6.2016).

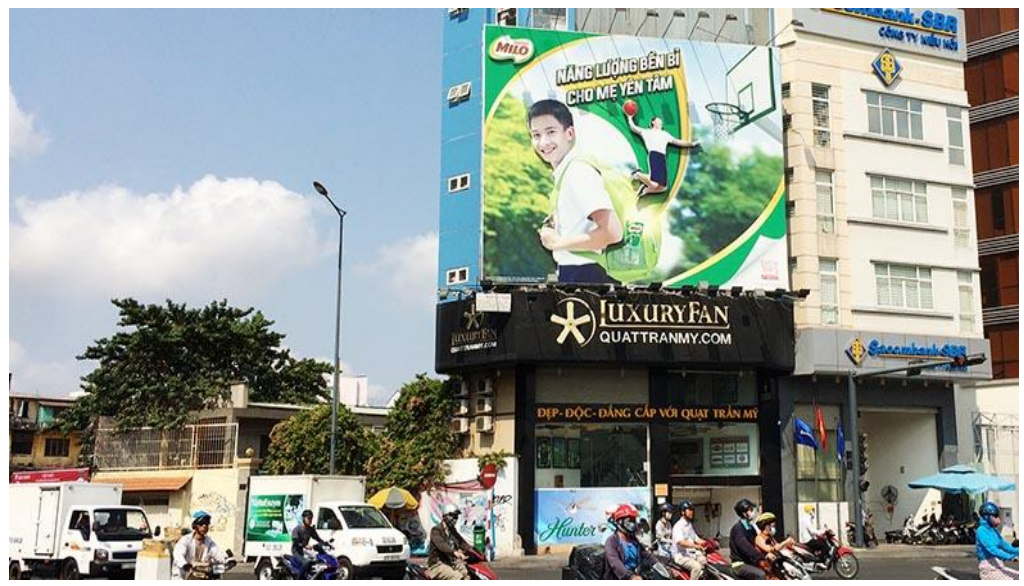

Fig. 12. Author took a photographs on Nguyen Van Troi Street, District 3, Ho Chi Minh City, Vietrnam. (3:40 PM, 6.6.2016).

\section{The expression of urban environment factors in advertising poster in Ho Chi Minh City}

Urban environment factors in the conception of advertising poster

From the viewers' point of view, the form will be appreciated firstly. However, the process of designing poster should start from concept to execution. The concept is not simply a disoriented idea but actually it is a process with detailed development in order to reach the communication requirement. It's also created from an adaptation of designer for having an understandable message. 
Normally, for having a good concept, designer has to answer different questions for a deeply understanding of the brand and its products as well as its consumers and cultural factors. They are the must for having a new meaningful idea of advertising poster.

For having a visually effected message, urban environment factors were created for new presentation. There are three approaches in creating key visual with development in environmental design factors.

Firstly, key visuals were created to emphasize the frequency, fragmentation, and continuation in a process, such as a story, that created aesthetic value of the commercial poster in urban environment.

In addition, key visuals were created to represent the every day's life images, with multifaceted perspective and inner messages. The way of looking for the model from reality and then stylizing it artistically had emphasized more on the meaning, which was pluralistic and had a combination of different values naturally and attractively. This is what it makes commercial posters nowadays have a new appearance in comparison with the previous periods in urban environment.

Besides, key visual of advertising poster with repressed relationships "containing the contradictions between illusion-reality, yes-no, reasonable- absurdity, natural- artificial, etc.“, according to Jacques Derrida; has formed complex relationships, and created ambiguity, implicitly, essential iconic symbols.

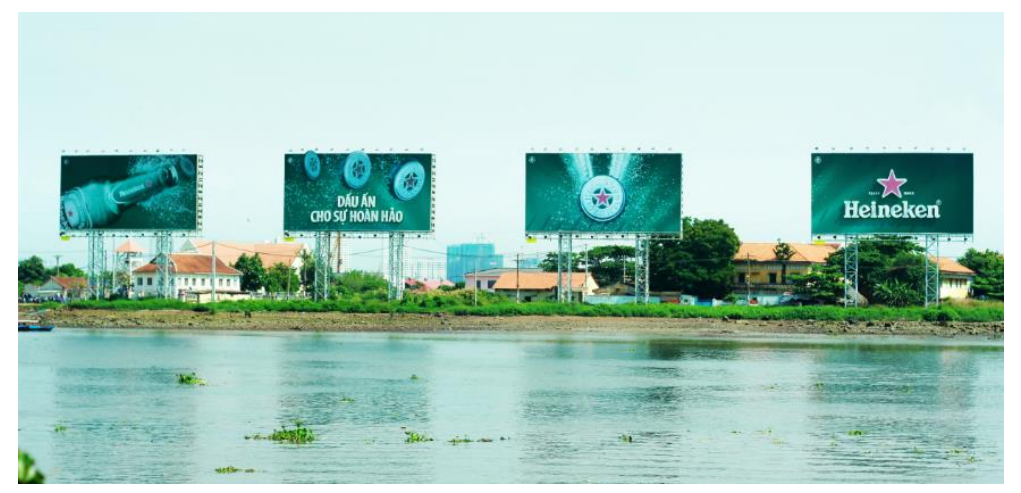

Fig. 13. Author took a photographs on Sai Gon River, District 1, Ho Chi Minh City, Vietrnam (4:10PM, 5.6.2016).

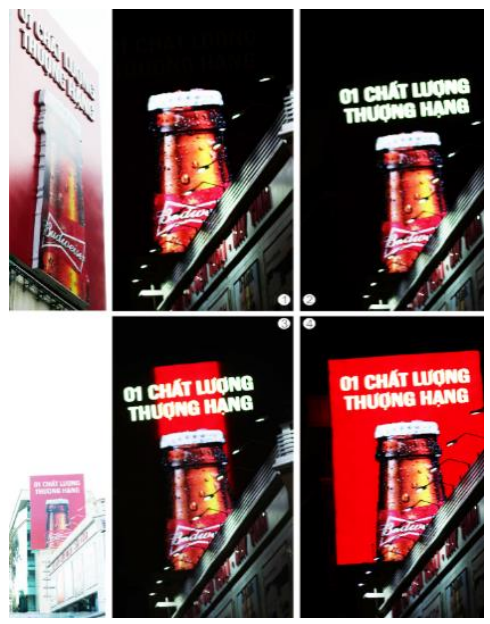

Fig. 14. Author took a photographs on Cach Mang Thang Tam Street, District 1, Ho Chi Minh City, Vietnam (4:30PM, 5.6.2016; 8:10PM, 5.6.2016). 
Urban environment factors in the expression of artistic form.

In color.

The color identification is always considered in commercial posters. Currently, this method has created lot of impact for visual communication art in environment.

First of all, the harmony of color combination almost has been replaced by a different factor, breaking the rule, which are not only the use of pure flat color but also the application of complex colors transition and the color of the used material. It mixed natural manners. There are more complex combinations, such as wide colors range, the mixing between photography and drawing, detailing fragmentation and the color transition for 3Ds effect, ect., which are used to emphases more on synthetically factor.

In addition, the principle of contrast is alternated, focusing more on rationale, concept. The colored characteristic is fully used with its nature and status because it can show the emotions and interactions of feelings in branding, in order to create individual identity in advertisement. Brand's colors merge into culture setting and targeted customers' characteristic naturally and flexibly.

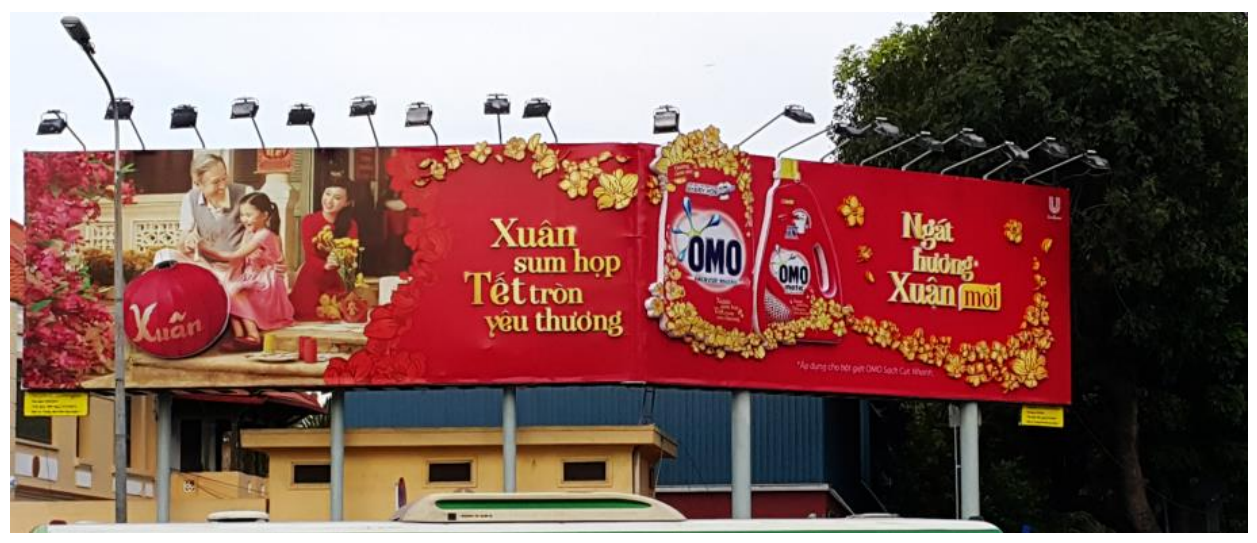

Fig. 15. This is an advertising poster for Tet Hoilday. Author took a photographs on Nguyen Trai Street, District 5, Ho Chi Minh City, Vietrnam (4:20PM, 7.6.2016).

In images.

Among of different kinds of idea expressions, image is a factor that shows the vividly the impression of urban environment. Today, images contain environment factors emphasize on the diversity of styles and techniques. That factor can be a photo, a geometric module, a line, and an illustration or it can be a photograph or signs, graphic symbols, etc. The created and recreated images focus on the scientific technology, which made images turn into multifaceted perspective, filled with integration and combination.

Besides, the eclectic elements focus on the image's impact or they can create a contingent approach to the subject matter. Even more, depending on the specific period of time, viewers can see the differences from different angles. In this approach, the images extend out of the frames and emphasize on the interesting interactions with viewers. This is to say, in commercial posters, only imagery creativity that can breakthrough the information barriers to perform its best on communication mission, to make sure that the messages will reach the public naturally and easily. Besides color, images, typography is one of the most important and indispensable factor for commercial posters. Typography itself is a complete work of art; words convey information and its own rules with the system of visual information symbols. In general, typography in advertising posters is the headline or the slogans that are presented the advertising's content briefly, and concisely. 


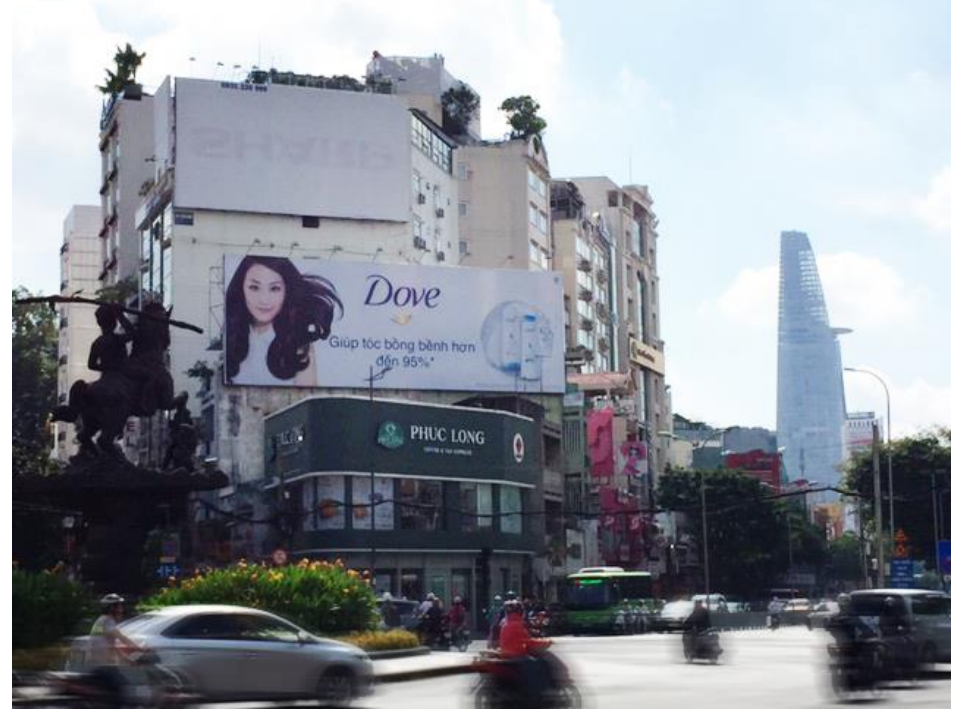

Fig. 16. Author took a photographs on Nguyen Trai Street, District 1, Ho Chi Minh City, Vietnam (10:60 PM, 10.8.2017).

Aside from the headlines that are always traditional, uplifting, literary, rational, meaningful and metaphoric, it is noticeable that the wordings expressing in commercial posters are influenced by every day's conversations. The text does not focus on grammar, looks like chatting, create intimacy and temporary humorous emotions that are suitable with the needs of aesthetic for today's commercial posters.

Besides the function of enhancing meanings of the images, typography is considered to be a part of expression in advertising design. In this situation, typography takes the role of a special image, basic depicting factor, and the text can be arranged, alternated, mixed, etc. in order to create an image with only the letters.

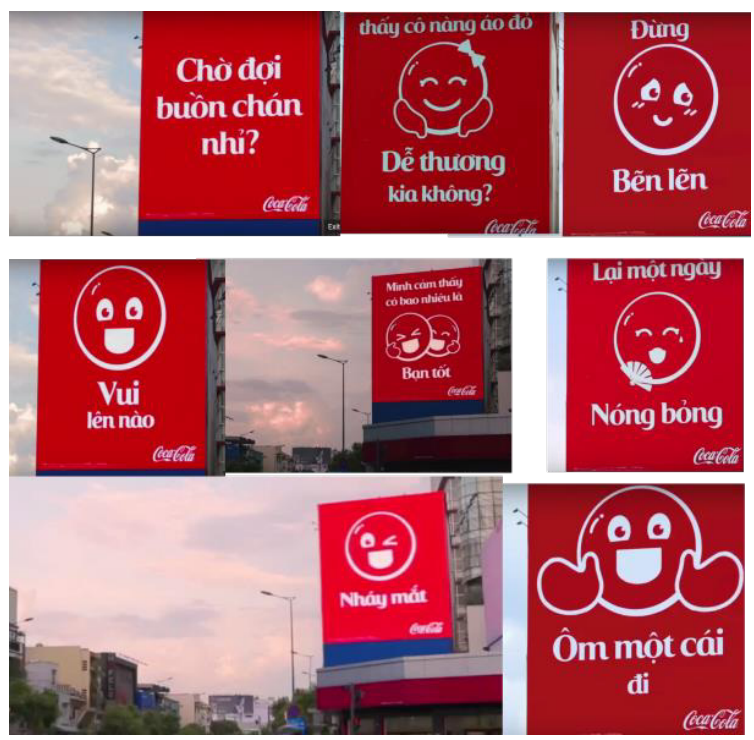

Fig. 17. Nam Ky Khoi Nghia Street, Tan Binh District, Ho Chi Minh City, Vietnam

(http://news.zing.vn/top-3-bang-quang-cao-gay-to-mo-nhat-cua-coca-cola-post561938.html (Tuesday, 9:07AM, 15.8.2017)). 
In composition.

Composition is a method to create artwork, including the applications of principles of relationships between all participated graphic elements in that artwork so that the meaning can be understandable. Colors, images and text can only demonstrate their own expressive ability and symbolic meanings when they are arranged in the right positions and proportions. However, today's urban environment elements have influenced the arrangement of advertising posters, which highlighted the alternation, irregularity, creating new appearances, unfamiliarity, and non-template in terms of aesthetics of composition. These characteristics have changed some conceptions of the poster's composition in comparison with the traditional commercial posters.

Firstly, oversized image, random arrangement, open composition, etc. are the ways to attract viewers' curiosity and make interaction with the public. These are the ways to explore different expressions on the composition and these styles are very common, likes a new vision of poster design that were brought in by urban environment elements.

Secondly, visual communication is highlighted in order to blur the boundaries of all types of art. The characteristics of eclectic elements with the combination of different types of art created a new creative nuance in commercial posters. The arrangement of composition and synthetically material contribute to the change of how commercial poster is defined nowadays, which is different from the common traditional poster printed on a flat surface. The way of emphasizing on the fusion of posters' expression and displaying or decorating style have instructed viewers how to "read" the message of a poster while it is held in an overall image with a good cooperation in order satisfy the idea's requirements, the inner feeling and emotion of the message.

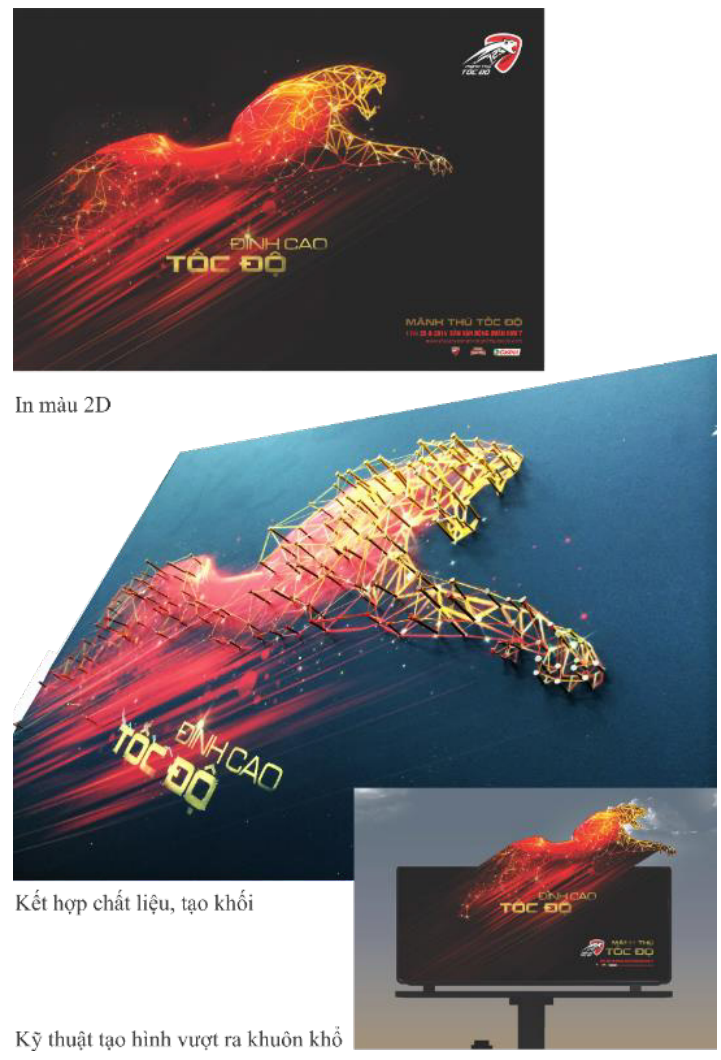

Fig. 18. Author: Hoang Thi Ngoc Han, 2016. 
In technology, technique and materials.

The fashionable concepts of listening, seeing, touching and non-touching civilization have created a framework for the formation of new design trends of advertising poster such as synthetic, focusing on the directed interactions to human senses in urban environment.

In terms of technology: In the movement of the world art history, every art revolution connected closely to a period of technology transformation and created a milestone by generating new artistic trends. Acquiring new scientific achievements and advanced technology such as design software's and design trends of the world, the designs of Vietnam are starting to participate, encounter many new opportunities and catch the new waves of advertising design. These elements have formed the colorful features of urban environtment for the current advertising posters.

In terms of techniques and materials: The industrial artworks must ensure its mission that is creativity along with the material, manufacturing techniques and production to make better services to meet human's needs physically and mentally. Techniques have opened a new way of communication for advertising posters. They are used as materials to create innovative waves in the aesthetic art forms of advertising posters. Those techniques are imposing creativity in design, considering the type of three dimension form open space, the posters and viewer's interactions, mockups, reliefs, making progress, making change, connecting with the peripheral morphology. Besides, the way of creating a random design's space, stimulating visual elements, making surprise effects, etc. are also used for transferring the messages.

The historical development of visual arts have always been a process to explore the new and innovative styles; in which, urban environment elements are a new perspective about aesthetics in the era of science and technology. This is a continuation of the journey of exploring to find a new voice of art, including thoughtful thinking, but not a change of expression; even though the new feature in an artwork is always easily noticeable.

Urban environment factors affected through the layers of expressions of visual languages are the materials to create figurative content in order to look at the overall linking factors that create the artwork's expression. Dividing the artwork's structure to notice the characteristics and methods of urban environment in every graphic elements: color, images, typography, composition, technology and technique, etc.; doesn't mean that all of the urban environment elements gathered on one design. It is the way to emphasize the effectiveness of urban environment in each element.

Based on the reality of a large numbers of advertising posters in Vietnam, this thesis has proved that urban environment elements have participated in and become more and more refined in creating key visual, which added a lot of aesthetic values to commercial posters in Vietnam. This value guided a new point of view of creative and enjoying artworks, impulse the economy and satisfied the shift of taste nowadays.
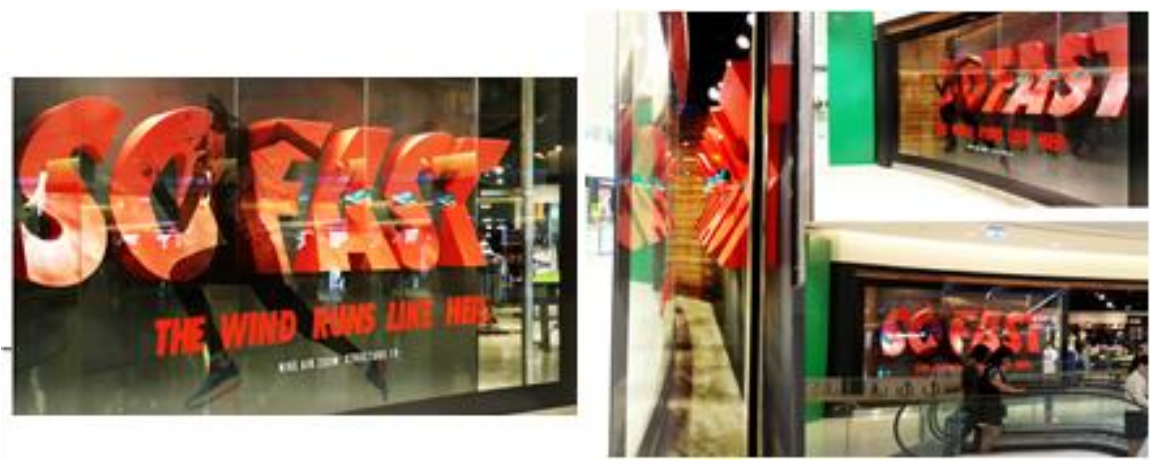

Fig. 19. Floor 3, Crescent Mall, District 7, Ho Chi Minh City, Vietnam (8:40AM, 9.5.2016). 


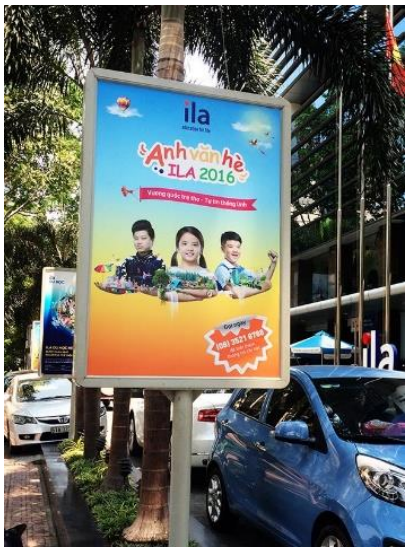

Fig. 20. Author took a photographs on Pastuer Street, District 3, Ho Chi Minh City, Vietnam (11:05AM, 4.6.2015).

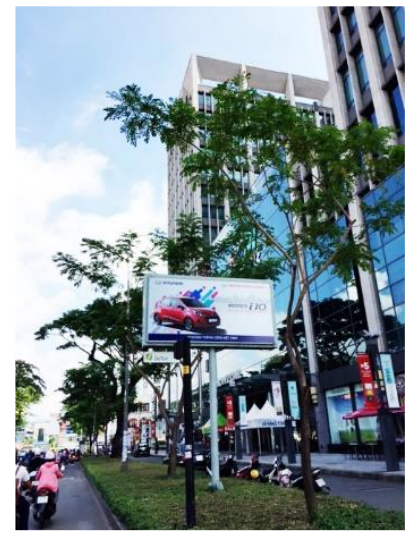

Fig. 21. Author took a photographs on Nguyen Van Cu Street, District 5, Ho Chi Minh City, Vietnam (9:25AM, 13.8.2017).
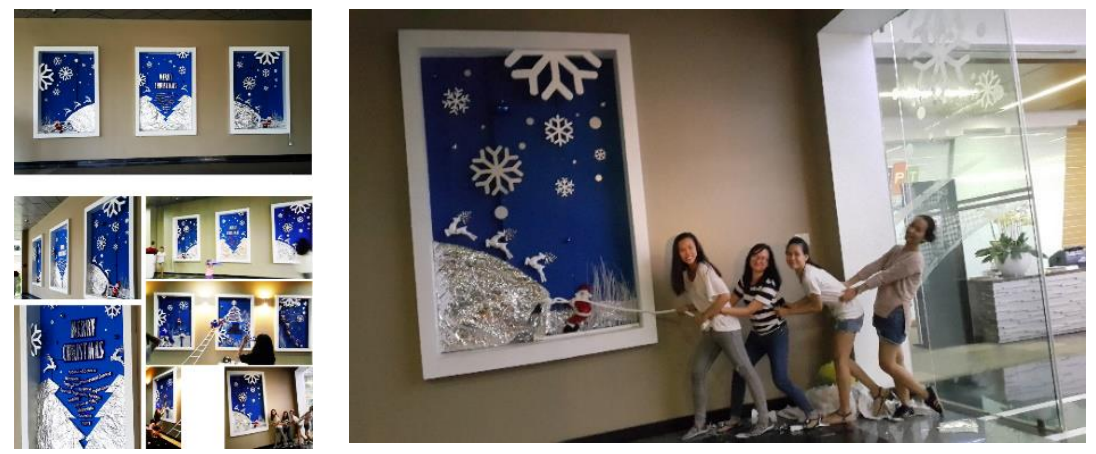

Fig. 22. Author: Nguyen Thi Viet Ha. Author took a photographs at Fsoft town, SaiGon Hi-tech Park, District 9, Ho Chi Minh City, Vietnam, 2015.

\section{The effectiveness and the development tendency of advertising poster influenced by urban environment factors in Ho Chi Minh City}

The effectiveness of advertising poster influenced by urban environment factors

Ever since the development of the market economy, advertising poster in Vietnam had and has been blooming. All the manifestations are considered for the targeted marketing, the integration of the communication in every advertising strategy is always highly appreciated. That may draw out some values to prove that the urban environment elements contribute to art, economy and the society.

Advertising poster influenced by urban environment factors contributes to change the artistic creativity's concepts

The young advertising design of Vietnam appeared when the European advertisement had already reached to their peak (flourished at the end of the 20th century), along with the advanced development of technology, science and technique, it had contributed to the appearance of advertising poster in the competition of the commercial market in the open trading period. From the approaching, explanation to the practice of art creativity in general 
and particularly in advertising poster; there is new perspective that reflects the new reality of the world according to the urban environment elements' characteristics, such as:

Firstly, urban environment factors are the harmonious combination of the traditional stereotypes and artistic methodology, and the expanding new concepts of art. Advertising posters have strongly transformed all the urban environment elements become Vietnamese, creating aesthetic in the combination of tradition and modern, East and West.

Second, urban environment factors are the diversification of the creation's methods associated with the need of the market economy and the reflection of the targeted viewers. Designing advertising poster is the harmonious mixture of the analytical thinking, reasoning and emotion, commercial and aesthetic, fusion and distinction, creative personality and nationality's characteristic, perfectionizing the profession.

Thirdly, it is the flexibility of mixing urban environment elements that makes advertising posters different from its original form. They highlight social values, community, and art symbol. This is the shift of ideology. Nowadays, most of advertising posters choose a level of specific characteristics and methods, which has urban environment elements to apply in order to make good effects in creating an artwork.

In general, as being an artwork that was formed from the needs of human life or to be precise, it is the commercial needs, advertising poster is different from the trend of creating art as "art for art's sake"- the artist only creates an artwork because of his/her own emotion or for the sake of art; on the contrary, the policy of designing artists in the field of applied arts is " art for life's sake" - which means that art must connect closely to life, serve human, and have a specific purpose.

Advertising poster influenced by urban environment factors contributes to impulse the development of the economy

Advertising user is an important factor in the change of advertising posters. It means that the awareness of those businesses participated in an advertisement have made decisions on aesthetic values of advertising posters; and conversely, advertising posters have changed the aesthetic awareness of Vietnamese enterprises nowadays.

Remarkably, advertising users have make urban environment factors expand such as: changing their desires, having new perspective in the idea's expression of advertising poster, actively finding a creative way to break the old form order, finding new ones. They emphasize on the design requirement that it has to be different from the traditional style to attract customers because they think "beautiful design makes business flourish".

Generally, advertising poster is the combination of aesthetic value and economic term, in other way, the success of advertising poster based on two core factors that cannot be separate which are function and aesthetic. The aesthetics of advertising poster is valuable when it satisfies the business' purpose and has economy efficiency. In the era that science and technology have reached its peak, while the differences in technical quality, ground costs and raw materials are all the same, artistic value will become the first element to compare and it is a needed factor to promote business and to compete in the market today.

Advertising poster influenced by urban environment factors contribute to orientate society

The only purpose of every creation of advertising poster is to draw public attention, to make them like, take into action and make them proud about the choice they've made. Therefore, the aesthetic expression must "awaken" the needs of the public, and those expressions are shown in urban environment elements. Advertising poster needs to uphold it's role as an artwork serves for the "life's sake". Advertising poster always begin from the requirements of life in a specific period of time and for a specific space.

The need of enjoying culture value in every social class is increasing rapidly and diversely. This means that, according to the law of supplying and demanding, it will stimulate the culture activities and make culture becomes more flexible and efficient. Urban 
environtment elements the reality of advertising design, the synthesis of styles in advertising poster, etc., have satisfied the high aesthetic demands of the society and affect human senses; they are somehow activate its vocation for exploring, inspiring, making impact and getting involved inspiration from the viewers. Through the valuable artworks, the public is offered knowledge, which gradually help them to raise their level of artistic enjoyment, and then, step-by-step to form an artistic taste.

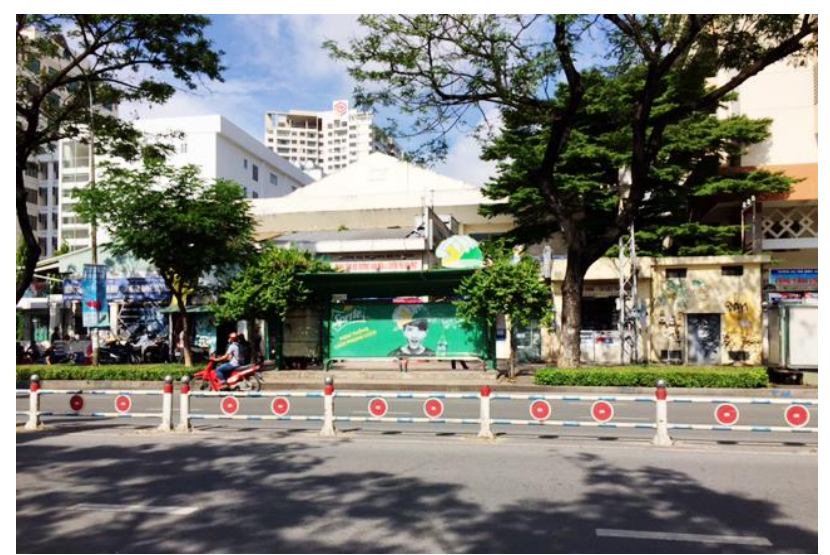

Fig. 23. Author took a photographs on Nguyen Van Cu Street, District 5, Ho Chi Minh City, Vietrnam, (10:18AM, 10.8.2017).

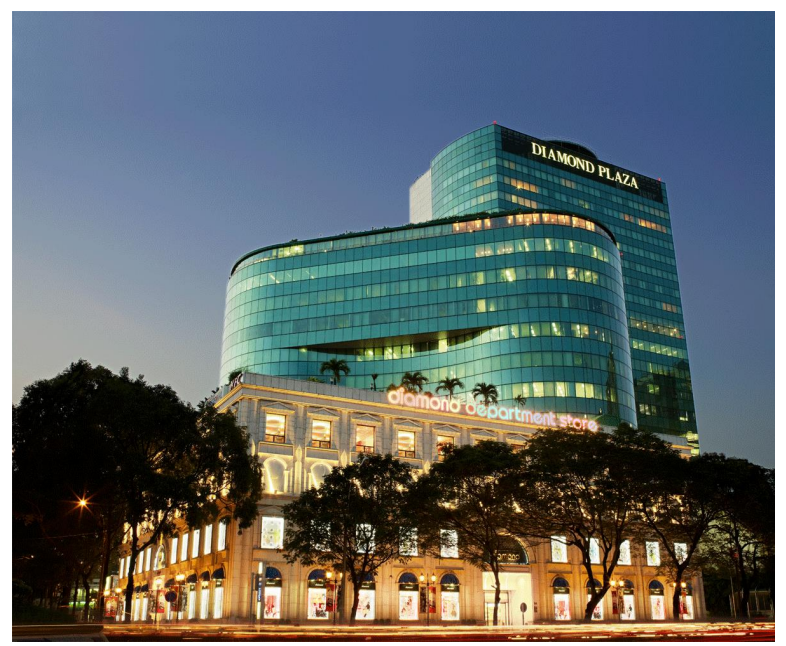

Fig. 24. https://www.bing.com/images/search?view $=$ detailV2\&ccid $=$ AMoMhMnE\&id $=$ 9A5CEFEB7E871C5D27C85DC1C9027E836A32A455\&thid=OIP.AMoMhMnEegpF4aZGpJbOFw EsD9\&q=diamond + in + Hochiminh\&simid $=608051183305558219 \&$ selectedIndex $=12$.

The limitations of urban environment factors in advertising poster

With the attraction of new aspects of art, a large number of designers tend to identify the source of effects as the same style practically without noticing its nature, origin, advantage or position in art in order to adapt himself to the new situation. As a result, the approach to urban environment factors, besides success, there are some disadvantages of quality and quantity of current advertising posters.

First of all, they are economic and aesthetic values. In traditional style, posters had to be printed in a large number and then be displayed on a surface quickly and economically. In contrast, those posters that need to emphasize on three dimensions embossment or 
installation, that expand out of frames or use special materials will need to have an analysis on specification and timetable, on the cost of workers, materials and technique. Sometimes, in order to have cost saving, the installation process of poster was shorten, roughly made or the materials of mixed standards was used for displaying that led to the low aesthetic effects of posters in Vietnam.

Besides that, the poster displaying planning of the city also affect on the aesthetics of advertising posters. Normally, the displaying places already have traditional frames and sizes. Those features had limited the show off characteristics of urban environment factors.

Further more, the environment of placing posters was not planned properly for visual aspects. Commonly, the posters displayed on electronic screens are expensive and time consuming but have low aesthetic effects. The main reasons are the existence of electricity wires network, layers of houses, stores, trees and signboards or even trash at the poster placing areas.

Another important factor is the viewers' perception is upgraded but without leading theories. As a result, among the developments, there are advertisements that pay no attention to cultural values. It is true that designer need to find new solution in his creation but it does not mean that every new approach is suitable with viewers. The new figures that are so unusual deformed with strong impact and extravagant images cannot exist on the national cultural.

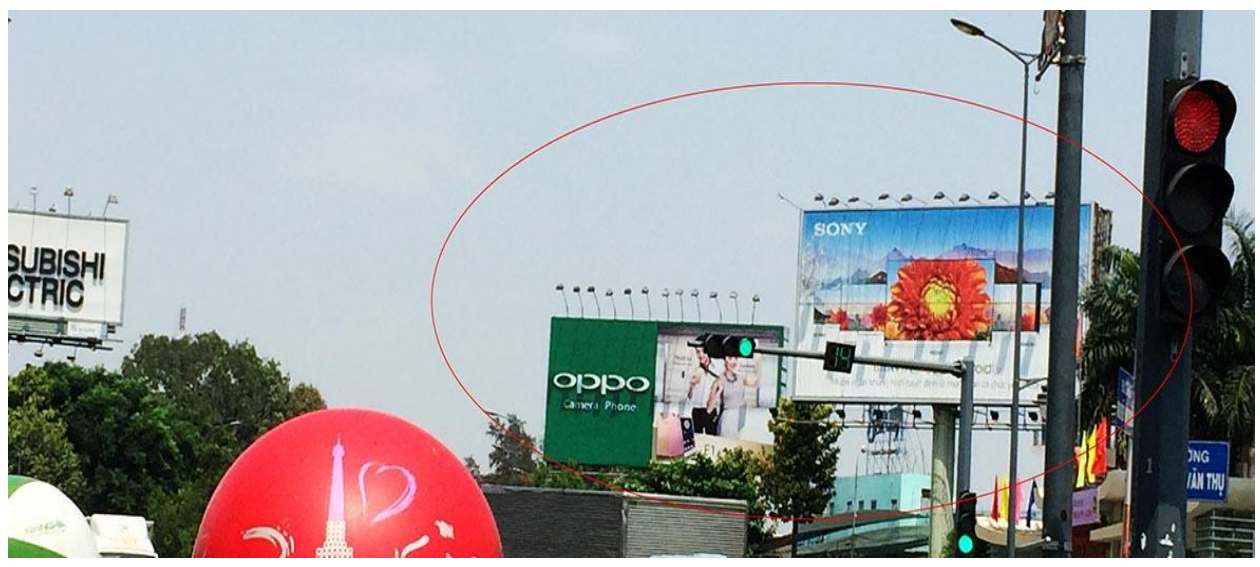

Fig. 25. Author took a photographs on Hoang Van Thu Street, Tan Binh District, Ho Chi Minh City, Vietrnam, (4:50PM, 9.8.2017).
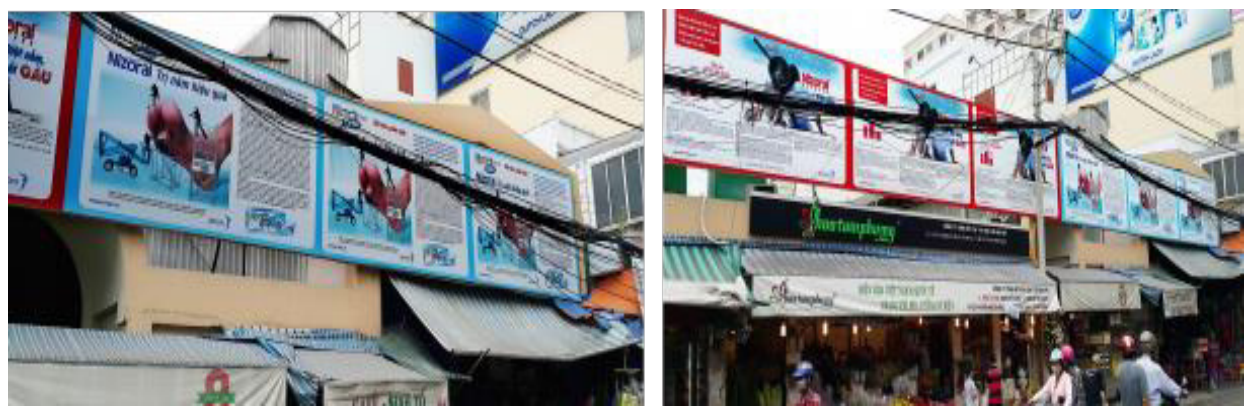

Fig. 26. Author took a photographs on Nguyen Thi Thap Street, District 7, Ho Chi Minh City, Vietnam, (9:20AM, 4.6.2016).

The trend of developing urban environment factors in advertising poster based on traditional aesthetic values 
A valuable artwork always has two elements: historical value and high distinctness. It can be seen that "historical value" is the cultural and traditional features. On the other hand, they are typical values that show the best object's origin that can be seen in all types of art or in daily activities. "A good idea is what we can memories the history and forms the differences for the future" Graphic Design for the 21st Century [70].

The social nature can be seen through phenomenon and a phenomenon is the existence of a specific nature of something else. There are changes when a phenomenon blended to an aesthetic culture. The urban environment elements of Vietnamese posters are different from those of other countries, as they are national characters. The urban environment origin elements with that distinctness cannot show all its nature when touching the common features of Vietnamese culture. Inheritance, innovation and development are the principles of culture. In case there are changes of principles that affect the objective reality, they cannot be considered as creating from new features without any relationship with traditional values. The movement and development of urban environment elements of Vietnamese advertising posters is an angle of view from reality development. When there is a new reality, there are new abilities that can be gathered in order to form a new reality. This sequence makes the development of urban environment factors and adapt harmoniously to the cultural environment of Vietnam.

Creating cultural impress is not easy for every work of art, but the awareness of those values is necessary for designing process. Traditional values are not stable but are formed and developed that are the foundation for new values. Continuous movement is an inevitable principle of nature, but the value that makes a character will exist and develop on different forms. Currently, urban environment elements are becoming a fashionable trend of design in general and of advertising posters in particular. Besides creating new appreciation of art, urban environment elements of advertising posters speed up the commodity economy and orientate the society. As a result, the issues of the urban environment elements development of advertising posters in particular and works of applied art in general, need to be aware in view of arts and culture adaptation so that the development trend works effectively.

Also, when the dialectical relationship between aesthetics and functionality, between tradition and modernity, between the imported and indigenous has been solved, urban environment factors would promote further its contributions as an indispensable. Then the traditional factors will be modernized to foster the cultural values for traditional art so that they all move together with the times.

\section{Conclusions}

1. "Urban environment factors in Advertising Poster in Ho Chi Minh City" is a new study approach and there is no other similar overall study on urban environment factors in Advertising Posters in Vietnam.

2. The article uses practical approach from empirical study to theory assumption and then reached core value of matter.

3. The article analyzed the effects of urban environment factors in Vietnamese Advertising posters. These factors lead to new approach in creating advertising poster: Breaking the rules, Interacting, three-dimensional look, three-dimensional Mock-up, Mixed medium, Variation that create a non-defining types of advertising posters in Viet Nam.

4. From artistic points of view, the article firstly focuses the relationship between function and Aesthete and secondly on the connection of Application and Art. These are objective points of view to acknowledge that urban environment have had big effects not only on the way to create Artwork but also on financial factors. And have enhanced social awareness in the era of globalization. 


\section{References}

1. Bui Van Danh, Matter of taste and Advertising (Saigon Cultural Publishing, 2007)

2. Dao Huu Dung, TVC Communications - to analyse and set a value on (Viet Nam National University Ho Chi Minh City, 2007)

3. Nguyen Thi Viet Ha, Art and Culture magazine 370, 53-57 (2015)

4. Nguyen Thi Viet Ha, Art Research Journal 2(06), 53-58 (2016)

5. Dang Thi Bich Ngan, Dictionary of art (Art Publishing, Hanoi, 2012)

6. Vo Hong Phuc, Achievements of economic - society through 20 years (1986 - 2005) (Political National Publishing, 2006)

7. Tran Quang Thai, Postmodernism - matter of theory (Tổng Hợp Publishing, Ho Chi Minh City, 2011)

8. Chu Quang Tru, Vietnam Cultural from art (Art Publishing, Hanoi, 2013)

9. Thai Ba Van, In Touch With Art (Art Publishing, Hanoi, 2009)

10. Phi Van, Advertising in Vietnam (Art Publishing, Ho Chi Minh City, 2007)

11. A. Chick, P. Micklethwaite, Design for sustainable change (AVA academia, 2011)

12. Bùi Như Hương, Phạm Trung, Vietnamese Contemporary Art 1990 - 2010 (Tri thức Publishing, 2012)

13. B. Munari, Design as Art (Penguin Global, 2009)

14. C.W.De Jong, S. Burger, J. Both, New poster art (Thames \& Hudson Ltd, 2008)

15. C. Bishop, Installation Art (Tate Publishing, 2011)

16. D. Parrish, T-shirt and Suite (2012)

17. G.H.E. Hawkins, Poster Advertising: Being a talk on the subject of posting as an advertising medium, with helpful hints and sensible suggestions to poster advertisers (Nabu Press, 2011)

18. H. Honour, J.Fleming, A world history of art (Laurence King Publishing, 2009)

19. J. Pavitt, Postmodernism: Style and Subversion, 1970 - 1990 (V\&A Glenn Adamson, 2011)

20. M. Gallo, The poster in history (Norton \& Co, 2002)

21. M. Gimenez, Advertising Graphic with Impact (Page one, 2010)

22. P. Osborne, Conceptual Art (Nxb Phaidon Press Ltd, 2011)

23. S. O' Donohoe, Always On: Advertising, Marketing and Media in an Era of Consumer Control (2011)

24. S. Heller, 100 ideas that change graphic design (Véronique Vienne, 2011) 